\title{
AC 2007-1166: BUILDING ENGINEERING COMMUNICATION SKILLS THROUGH SHORT ASSIGNMENTS
}

\section{Joseph Tranquillo, Bucknell University}

JOSEPH V TRANQUILLO is an assistant professor of biomedical and electrical engineering at Bucknell University. Dr. Tranquillo teaches courses primarily in bioinstrumentation. His research focuses on theoretical and computational models of electrical activity in the heart.

\section{Daniel Cavanagh, Bucknell University}




\title{
Building Engineering Communication Skills Through Short Assignments
}

\begin{abstract}
Engineers are expected to be able to communicate via memos, abstracts, graphics, brief communications and oral presentations. Communication skills, however, are often practiced in an undergraduate engineering curriculum either through detailed and lengthy laboratory reports or final oral presentations. The authors have developed a generic sequence of short assignments that build skills needed to produce a final written oral or graphical communication. Each short assignment focuses student attention on a particular component of the final communication. For example, in a sophomore-level Fundamentals of Biomedical Engineering class, students are challenged to report results of a hands-on activity using only a single graphic and 200-word explanation. As students become more effective at conveying their ideas in individual sections, the emphasis can turn toward transitions between sections. After following this sequence, the final communication may be assigned with few explicit instructions aside from format. Limiting the space or time students have to convey ideas may also be applied to the final communication. For example, in a junior-level Biomedical Signals and Systems course, students are challenged to explain semester-long projects in a two-page IEEE format article and 20minute presentation/demonstration.

The instructional model works equally well with written, oral or graphical communications and is well suited as a parallel to a large course project. Limiting the space and time to convey ideas has the added benefit of focusing student attention on the important technical objectives of a laboratory exercise. After implementing this instructional model, the faculty have observed a rise in the quality of written, oral, graphical and technical work. Furthermore, end of course evaluations indicate that students understand how the sequence of short assignments develop technical communication skills.
\end{abstract}




\section{Introduction}

All too often the authors' have received reports that are 30 pages long with page upon page of text, tables with raw data, figures for every possible combination of variables and several appendices. This is clearly a brain dump by the students in the hope that eventually they will include exactly what the professor is looking for. The same is often true for graphical and oral presentations. It is this type of unfocused communication that we, as educators and graders, are concerned with overcoming. This paper outlines a new tactic in teaching writing to engineers that compliments their technical abilities and prepares them for communicating in a professional environment. Three points are listed below as motivation.

\section{Motivation 1: Teach them what they will use later}

While the traditional engineering curriculum places great importance on the lab report, most students will graduate and never write another lab report (8-9). Lab reports are useful to prepare students for hypothesis-driven scientific writing and thinking, where final results are presented in one paper or presentation. Practicing engineers, however, do not explicitly create or communicate new science. Instead they communicate their incremental progress on a design or project in a variety of written, graphical and oral communication forms.

Motivation 2: Reduce busy work to focus on quality

Repeatedly assigning an excessively long communication eventually leads to diminishing returns in both the quality of the work and the learning that takes place. When students spend more time writing the lab report than thinking about content, the result is busywork for both the student and grader.

\section{Motivation 3: Keep things fresh}

A number of studies have demonstrated that students retain and transfer knowledge and skills to new situations when they must communicate their knowledge in a different form than it was received (1). This is the reason why simply copying/modifying information from a lab protocol to a lab report does little to help students learn material.

\section{General Approach}

The research literature on engineering literature is rich with ideas on improving the communication skills of engineers $(2-5,11)$. The general approach presented here is to limit the time and space students have to communicate ideas so they can focus on quality representations of their work. Assignments are more frequent, but shorter and more focused on specific writing and technical skills. A significant strength of this approach is that students must develop critical thinking skills to distinguish between important and unimportant information.

We first present a number of written, oral and graphical assignments the have been implemented in the following courses: Fundamentals of Biomedical Engineering (BMEG 210, fall sophomores), Introduction to Engineering Computing (BMEG 220, fall juniors), Biomedical Signals and Systems (BMEG 350, spring juniors), Biotransport (BMEG 300, spring juniors) a Research Methods Sequence (BMEG 408/409, fall junior and spring 
seniors), Neural Signals and Systems (BMEG 472, senior/junior elective) and the Senior Capstone sequence (BMEG 401/402, seniors). Second, additional writing characteristics are addressed such as the roles of revision and group work as well as importance of audience. The authors conclude with observations on the implementation of the assignments.

\section{Types of Assignments}

The Modified Lab Report

The traditional lab report has become the staple of engineering classes for a reason. The authors certainly do not wish to imply that there is no place for the lab report in engineering classes. In fact, early in an engineering curriculum the lab report is a safe and familiar means of assessing student learning. The sections of a lab report (e.g. introduction, conclusion), however, can be of value on their own. For example, the exercise of writing an introduction, given only oral instructions, is an excellent way to assess if students understand the purpose of the lab and its context within the class.

A typical assignment in BMEG 210 or BMEG 350 (See Appendix A) directs students to create a single graph or table that summarizes their data from the lab (See Graphical Section below) accompanied by a short description. A word limit is generally placed on the description (e.g. less than 200 words). Alternatively, directions to complete a task may be given orally and the students must compose a brief methods section.

\section{Writing Development Exercises}

One hurdle for both the instructor and student is an understanding that the writing process is highly non-linear. This is for two reasons that should be made explicit to the students. First, the starting point of most writing assignments is known but the ending point is often unclear. Writing can be a powerful method for brainstorming, exploration of ideas and assessment of a number of possible ending points. From this viewpoint, writing is a tool to be used to think more deeply about a topic or problem. Second, once the end point is determined a clear trajectory must be mapped out for the reader to get from the starting point to the ending point. It is the paradox of writing that the process is nonlinear but the written document often is linear.

We have found that short, upgraded writing assignments (e.g. minute papers) are an excellent way for students to practice writing without the fear of harming their grade (1). In-class writing exercises are also a mechanism for students to synthesize information they have just learned. For example, in BMEG 210, class is sometimes concluded by asking students to write about a real-world problem that can be solved using course material. In BMEG 210 and 350, some labs are conducted as demonstrations with a reflective writing assignment to be completed in class. Alternatively, a short written assignment (e.g. individual or group brainstorming session) at the beginning of class can be used to increase student engagement in the material. 


\section{Professional Writing Skills}

Along the lines of motivation one (teach them what they will use later), building professional writing skills can be a very valuable investment (8-9). These include but are not limited to:

$\begin{array}{ll}\circ & \text { Memos (Appendix C) } \\ \circ & \text { Emails } \\ \circ & \text { Abstracts } \\ \circ & \text { Problem statements } \\ \circ & \text { Alternative solution reports } \\ \circ & \text { Design notebook entries } \\ \circ & \text { Budgets with justification } \\ \circ & \text { Executive summary }\end{array}$

The senior capstone sequence (BMEG 401 and 402) places significant emphasis on professional writing skills. After many years of technical writing, it is important that students understand the value in writing a professional (non-technical) document. One possible motivator is to ask students what they plan to be doing after they graduate. Typical biomedical engineering programs send students to graduate school, professional or medical schools or industry. It is common for all of these pathways to lead to a management role.

Since students generally have limited exposure to professional writing, it is helpful to pass around a tip sheet with points to consider (Appendix C). For example, in BMEG 401 , students must write a one-page memo each week to update their mentor based upon a tip sheet they receive the first day of class. As the semester progresses, and students become more effective memo writers, they receive additional tips that help refine their communications.

\section{Graphical Presentations}

Most students are familiar with the saying, "A picture is worth a thousand words" and thus include as many plots, charts, figures and tables as possible. What many students fail to realize is that a poor graphic is the same as one thousand words of rambling. Conversely, a good graphic may represent far more than one thousand words. First, students should be focused on the basics of graphical presentation, including line thicknesses, axis labels, captions, and citations in the text (2). These basic skills are addressed in BMEG 220. The authors, however, have received perfectly formatted plots for every trial in an experiment. Collectively, all the information was present but the conclusions were only made for the reader in one sentence at the very end of the report. A second, and possibly more important, focus for graphical presentations is to condense a large amount of data into a single summary graphic. In many lab assignments across our curriculum, students are limited to one summary figure or table (Appendix A). A similar limitation may be placed on schematics for experimental setups. For example, in the BMEG 350 Project (Appendix D), students are encouraged to condense their experimental setup into a block diagram where all feed forward and feedback loops as well as controllers are identified. Lastly, the creation of posters give students the 
opportunity to integrate several graphics into a coherent story (Appendix E and section below).

Oral Presentations

When students hear the words "oral presentation" they seem to immediately reach for their laptops, bring up PowerPoint and begin making slides with animated text, fancy graphics, movies, bells, and arrows. While this is not the worst reaction, they should understand that effective oral communication is based upon clear and efficient use of words supplemented by strategic text and easy to understand graphics (See Previous section) $(5,7)$.

The traditional limitation in oral presentations is the time for the presentation and followup questions. This approach was used in BMEG 210. Students have 12 minutes of presentation and 3 minutes of questions to communicate their design projects. They are not allowed to use notes. In addition to technical content, speed, flow, audience engagement (eye contact), precision, attractiveness of slides and organization are evaluated. In BMEG 350, an additional twist was added. Students were given 20 minutes to not only present but also lead the class through a live demonstration of their semesterlong project (Appendix D). An alternative to limiting time is to limit the number of slides. This tactic was used in BMEG 408 where students had five slides to get their point across. Yet another oral communication tactic is to only allow graphics.

The instructor should be aware that time, slide number or word limitations focus students on different aspects of a presentation. For example, limiting the number of slides causes students to carefully consider what information they must communicate. Only allowing graphics requires careful planning and organization of the presentation.

A poster presentation (Appendix E) is also an effective means of communicating ideas. In BMEG 300, students were limited by the typical size restriction (40 by 60 inches). There exist, however, other useful limitations such as number of words or figures. A particularly useful twist is to limit the length of time students have (e.g. 2 minutes) to explain their poster. This tactic was used for a summer REU program. It should be pointed out that at scientific conferences, the average passerby may only wish to hear 1-2 minutes on the most important points. The student, however, should be able to speak at length about any specific aspect of the poster if asked. Posters also provide an opportunity to visually present data in a non-linear fashion. For example, the poster may be organized around a central graphic, motivational statement or result. In this manner, the poster is not stand-alone but can be used effectively as an aid.

\section{Sequences of Assignments}

All of the above tactics may be used to build a foundation of skills from which students can compose a larger final communication. In fact, we have found that the most powerful use of short assignments is in preparation for a larger assignment. There are two possible pathways toward the final communication. First, short communication assignments may be small vertical steps toward a larger assignment. For example, in BMEG 401 students must turn in regular written assignments (e.g. problem statements, solution abstract, 
feasibility tests) in preparation for a final oral presentation and final design proposal. The final design proposal is composed of these individual assignments, linked together by transitional language and sections. Second, short communication assignments may be used to parallel a larger assignment. Here the content of the specific assignments will not be used in the final document, but will build writing and thinking skills that will be necessary for the final assignment. For example, in BMEG 210 the written lab assignments are used to practice writing specific sections (e.g. introduction, methods, figures and tables, conclusions). After completion of a semester-long project, they are challenged, with little direction, to write a four-page IEEE-format paper. The goal of this final assignment is for students to transfer the skills they worked on in isolation to a larger assignment.

For both vertical and parallel assignments the following algorithm is helpful:

- Develop the desired final format (written, oral, graphical or combination)

- Develop a rubric that divides technical and communication attributes.

- Develop assignments that separately target each attribute.

- Grade only on the students' abilities to focus on this attribute.

- Work on transitions after each attribute has been practiced.

- Provide time to develop the final product.

The authors have found that for both vertical and parallel sequences, most students realize that they are building skills that will be useful in their final communication. Once students make this realization, they do not view their assignments as busy work and are well motivated. Although the authors have only experimented with vertical and parallel written assignments, it should be possible to build toward an oral or graphical communication. For example, a vertical approach to a final poster would be to assign bullet points that summarize various sections of the poster.

\section{Assignment Characteristics}

\section{Revisions}

All too often, students begin at the beginning and write until the end. Diligent students will revisit their work and reorganize, cut, add and modify as needed. It is important for students to understand that the first draft of a document is rarely well executed. To emphasis the importance of revision, students should be granted the opportunity to revisit some of their writing after they have submitted a first draft. In BMEG 210, a preliminary proposal is written and then revisited later in the semester in the form of a final proposal. The same written work is then visited again when sections of the final proposal are incorporated into the final document. A similar progression is used in BMEG 350.

Although it can be difficult for students to iteratively improve a presentation once delivered, the goal of the instructor here can be to highlight improvements for the next presentation. In BMEG 401 final presentations were evaluated by the instructor and peers. Following the presentation, the instructor provided verbal feedback but also gave the students a summary sheet of numerical scores and comments from their peers. In BMEG 408, student improvement was stimulated by video taping presentations and 
requiring students to privately view their presentation. This type of self-reflection can quickly highlight the good and bad presentation habits of individual students.

\section{Group Work}

As in motivation one, professional engineers will often write documents as a team. Any of the above communication ideas may be assigned to a group of students. In fact, many of the final communications used as examples above, were assigned to groups. Group writing brings special challenges related to teamwork which we will not expand upon here. One helpful guideline, however, is to assign responsibility for various sections to prevent one person from assuming the role of "writer" for every assignment. It should be noted that groups naturally lend themselves to peer assessment of writing as a mechanism for revision. A slight twist on group assignments was used in BMEG 401 to highlight the challenges of group communication. The entire class (13 students) was challenged to create a single graphic and present it in class, to the instructor, 48 hours later. The results of this exercise were used to motivate a discussion of large group dynamics and management.

\section{The Importance of Audience}

For all assignments it is important that students consider their audience. Most of their lives, students have been satisfying an instructor who will use their communications to assign a grade. It is the perpetuation of this format that leads to the "brain dump". Unfortunately, the brain dump is often rewarded and students get the message that length is an indicator of time spent and thought invested. The authors have found that varying the target audience (e.g. another student, potential employer, a child, a busy executive) of a communication can help students recognize the need to adjust the style and content of a presentation. For some audiences, it is appropriate to take on the role of teacher. For other audiences, it is more important to sell an idea. The pace, level of detail, emphasis, tone, and degree of formality must change to meet the audience at their intellectual and interest level.

To highlight the importance of the audience, it may be useful for students to either communicate information to different audiences in separate works or communicate information to a varied audience in one work. In BMEG 472, students were required to prepared four written works all centered around a particular topic in neuroscience. The first three short works were targeted to a layperson, clinical scientists and engineer respectively. These works included children's books, science fictions stories, medical pamphlets, and video tutorials. The fourth work was a reflective written statement comparing and contrasting the approaches used to convey the same material to three different audiences. In BMEG 401 weekly memos were addressed to fellow team members, the faculty advisor and external clinical mentors (Appendix B). For oral presentations, the role of the audience may be made more acute by inviting the target audience. For example, in BMEG 401, the students' external mentors were invited to attend project presentations. All of these tactics aim to ease students out of the mindset of only presenting for the professor. 


\section{Observations and Assessment}

As our program is new, many of the assignments above were implemented in the first offering of a course. It is therefore difficult to compare our approaches to traditional assignments. We are currently in the process of devising direct assessment rubrics for our assignments (See Appendix C). In the future, our program aims to develop generic assessment rubrics for distinct modes of communication that may be used as-is or modified for specific assignments. The development of these rubrics will be an evolving process and based upon our observations of student work. The goal of these rubrics will be to confirm or deny our observations and generate hard data for ABET direct assessment. Below, we offer our early observations on assigning short and focused communications:

- Increasing the frequency of assignments, while decreasing length, does not necessarily alter the amount of time spent grading. The shorter assignments are generally easier to grade since they enable a quick assessment of if a student has "gotten" the main technical points. On the other hand, if the primary purpose of the assignment is to focus more attention of the quality, the instructor has a responsibility to more carefully consider the most useful feedback for the student.

- Courses taught using some combination of the techniques above may satisfy a university writing requirement. At our institution, all students must complete three courses designated as writing courses. The ideas in this paper were used to construct our senior capstone writing experience which was well received by our Writing Center.

- The assignments may satisfy departmental ABET requirements (criterion 3g).

- Although the instructor may not explicitly state it, some students draw the parallel that communicating within constraints is virtually identical to engineering within constraints.

- It is often the case that students do not have the opportunity for improvement on onetime communications (i.e. final presentations). We have observed, however, that feedback in one course is translated to future courses.

- One danger in short and frequent assignments is that procrastination on the part of the instructor is much more damaging than in the traditional approach. Students will become frustrated if they must turn in an assignment without having feedback on a previous assignment.

- It is important to have some rubric that is communicated to the student. Otherwise, students may have the impression that grading is subjective. In reality, the grading of writing is somewhat subjective but a rubric can help both the student and instructor define the expectations and general philosophy underlying an assignment. Another form of rubric that we have used is to hand out a "tip" sheet with points to consider (Appendix C).

- It can be helpful to either grade later version of assignments or having a grading scale that weights the end assignments more heavily. Students have expressed that constructive comments are much more helpful than an numerical grade. This approach helps students with strong writing skills because they invest significant time upfront and then have reduced workload as the semester progresses. The approach also helps students with weaker writing skills since they are rewarded for improvement throughout the semester. 
- Students often have the preconceived notion that writing a long document is more difficult than writing a short document. The initial reaction to short writing assignments is therefore relief. This relief evaporates when student realize that composing a shorter document is in fact harder. It is important that they understand that it is harder because they are not being allowed to simply brain dump information but must process it for the reader (and thus themselves as well).

- Any of the ideas in this paper may be combined into a hybrid assignment. For example, the results of a project may be presented as an oral poster presentation that combines both oral and graphical elements.

- In BMEG 350 students were asked to respond to the following question: "Short and focused written assignments were more effective than full lab reports" This question scored a 4.83 on a 5 point scale.

\section{Conclusion}

A goal of any engineering curriculum is to graduate effective communicators. Communication skills, however, are often practiced in an undergraduate engineering curriculum either through lengthy laboratory reports or final oral presentations. In this paper, the authors present an alternative approach based upon more frequent but shorter assignments. The general tactic is to challenge students to write or present within time and space constraints.

Our entire program devised the concept of short assignments and therefore communication skills are stressed by all instructors in all courses. The specific short assignments and their sequence, however, are up to each instructor. To ensure that a variety of skills are addressed, the faculty regularly share assignments. This is possible in a small program. Program growth will necessitate a more systematic approach that includes direct assessment within individual courses and across the curriculum.

In summary, our faculty have observed a rise in the quality of written, oral, graphical and technical work following the implementation of short assignments. Spread liberally throughout the curriculum, we believe our approach allows students to practice a wide range of useful communication and critical thinking skills that will serve them well upon graduation.

\section{References}

1. How People Learn" National Research Council. 2000. http://www.nap.edu

2. De Graaf PW, Wright CHG, Welch TB, "Evaluating and Improving Student's Technical Presentation Skills," Proceedings of the 1999 ASEE Conference

3. Ford, J and Riley L, "Integrating Communication and Engineering Education: A Look at Curricula, Courses, and Support Systems," J of Eng Ed. 2003

4. Gunn C, "Integrating Communication Skills into a Mechanical Engineering Department," Proceedings of the 2006 ASEE Conference.

5. Kozak, MR, "So You Have a Presentation?!," Proceedings of the 2005 ASEE Conference.

6. Manuel-Dupont S, "Writing Across the Curriculum in an Engineering Program," J of Eng Ed 1996 p. 35-40 
7. Morello, J, "Comparing Speaking Across the Curriculum and Writing Across the Curriculum Programs," Communication Education. January 2000

8. McNair LD, Norback JS, Miller B, "Integrating Discipline-Specific Communication Instruction based on Workforce Data into Technical Communication Courses, “ Proceedings of the 2005 ASEE Conference.

9. Norback JS, McNair LD, Laughter MJ, Forehand GA, Sutley-Fish, B, "Teaching Workplace Communication in Industrial and Electrical Engineering," Proceedings of the 2004 ASEE Conference

10. Rutkowski G, "Electronic Portfolios for Engineers," Proceedings of the 2006 ASEE Conference

11. Wilk RD, Anderson, AM, "Development of Communication Skills Across the Engineering Curriculum," Proceedings of the 2002 ASEE Conference

\section{Appendix A: A Typical Lab Assignment}

The following directions are provided to a student in BMEG 210 following the recording and scoring of multiple three-lead ECGs from all lab partners. The concept of an ECG was introduced in class and discussed orally prior to the lab.

1. Provide an introduction (200 words or less). You may want to include:

a. Why is the ECG important?

b. Why is computing ECG intervals important for diagnosis?

2. Provide a single representative ECG labeled with the PQRST waves

3. A summary table of your interval measurements. Remember to properly format your table.

4. Summarize your data (200 words or less). You may want to include:

a. Where there any trends in your data?

b. What problems did you encounter?

\section{Appendix B: BMEG 401/402 Electronic Design History File}

As part of the BMEG 401 course, student groups were required to keep a paperless design history file. The instructions provided to the student are below. The written memos, emails, meeting minutes and project assignments that are referenced all have separate instructions.

The design history file is intended primarily to serve as a history of engineering and research developments whether they materialize into commercial usage or not. It is to be used as a technical diary and calculation book. In addition to its value for documenting project progress, history files are essential for establishing intellectual property which is a primary concern of industry. In order that the file best fulfills its purpose, certain rules should be followed:

1. All entries must be complete enough to be understood by another engineer. (If you look at an entry a week later and cannot understand it, the entry fails this rule.)

2. Every idea, conference, or event which may have bearing on developments should be entered. 
3. All calculations should be entered.

4. Place the date at the top of each entry. If you start a day's entries in the middle of a page, head these entries with the correct date.

5. Any sketches should be signed and dated. In case a sketch of an idea seems worthy of some consideration, have this witnessed by two other persons. Description of the idea should accompany the sketch.

6. Do not erase or obliterate entries. In case of changes or improvements to an original sketch of an idea, make a second sketch. If a calculation is found to be erroneous, make a note of the previous error and enter a second (correct) calculation under the current day's entries.

7. The following documents should appear in your DHF:

- All memos

- All emails sent relating to your project

- All meeting minutes

- All drafts of project assignments

8. When submitting your DHF for review, you should include a table of contents.

9. For further information on DHFs, you may wish to consult King and Fries p. 87-89.

As in most industrial settings, the DHF for BMEG 401 will be entirely electronic. While some information will lend it self to electronic entry (i.e. memos), some may not (i.e. preliminary sketches). To include drawings, calculations, lists etc., you will have 24-hour access to the Document Scanner in Dana 217. The combination to this room is XXXX\#. An in-class session will familiarize you with how to digitize hardcopies to pdf files and have them emailed to you.

\section{Appendix C: BMEG 401/402 Memos}

Throughout the senior capstone, students are required to write memos that are distributed to their team, faculty mentor and external advisor. The external advisor is a non-engineer with clinical training.

\section{Weekly Memo Guide}

You are required to write weekly memos to the BMEG 401 faculty as well as your external mentors. As with any business communication, it is very important to be clear and concise. You must make several revisions (as a team) in order to thoroughly communicate your ideas in a clear and concise manner. A typical length for a memo should be one page and should rarely (maybe never) exceed two pages. Any drawings, calculations or supplementary writing should be included in as addendum to the memo.

Each memo should contain the following information:

1. A brief statement of past work. This will remind the reader of the overall purpose and progress of the design. Only 2 or 3 sentences are likely needed here, but they should be carefully worded.

2. A discussion of efforts since the last memo. This is the main body of the memo and will take up the most space. You must report which team members were responsible for each task accomplished. 
3. A brief statement of your intentions for efforts over the next period. You must report which team members will be responsible for each task.

4. Any action items that you require from your external mentor should be clearly stated and easy to find. You should also include the date that you would appreciate receiving it. Remember, your external mentor is busy so you should schedule enough time for a response.

The team memo must be emailed to the course coordinator, faculty advisor and external mentor by NOON on Wednesdays. In addition, you must include a copy in your design history file.

\section{Memo Tip Sheet 1}

Structure

- Begin with a standard heading

To: $\quad$ (Make sure the readers have been addressed by the proper titles)

From: $\quad$ (Team member names and initials)

Date: (Write out the date - e.g. August 28, 2006)

Subject: (Make the Subject line something specific and concise)

Attachments: (List the title of the documents)

- Start by reminding your reader of the previous and current status of your project.

- Continue by explain the progress that was made since the last memo. Place initials of the team member(s) in parentheses who competed each task listed.

- End by explaining the actions you or your reader(s) should to take. You will want to think about how these actions will benefit your reader so you can respectfully frame your requests. It is appropriate to request a date by which you wish to have a response or action completed. Be sure to provide a reasonable length of time. If a meeting is desired, stated the intended purpose.

- Sign the memo with "Respectfully Submitted" followed by your names.

Mechanics

- Turning in a first draft of a memo is NOT acceptable.

- Remembering that your readers are Dr. Tranquillo, your faculty advisor and your external mentor will help you focus on the information we need to know.

- Conveying important information is best as bulleted lists. Be certain that lists are in parallel grammatical form.

- Beginning lists or writing with short topics headings will help direct your readers.

- Referring to attachments in the memo will bring them to your reader's attention.

- Using "I" and "we" is okay in a memo.

- Using fonts smaller than 12 point or larger than 16 point is not encouraged.

- Spacing text and centering will improve the professional appearance of the memo.

- Including the Bucknell seal will also improve the professional appearance of the memo.

Memo Tip Sheet 2 
As you become more comfortable with the mechanics of writing memos, you will wish to increase the effectiveness of your memos by refining your style. Below are some additional points to consider:

1) Beginning a sentence with "This" it is usually a writers attempt to link the current sentence with a previous idea. It is often unclear to the reader what "This" refers to. The previous idea should be connected to the current statement more clearly.

2) The adjectives you use to describe activities and items should be as precise as possible. For example, there is a more precise way to say a solution is "nice".

3) A memo is not a place to complain or make excuses.

4) Use prudence in what you write down. There are some statements you may want to say but not write down.

5) Some verbs are not precise or professional. It is better to use action verbs to explain a finding or task completed. For example, writing that your group "did" something is a weak statement. Likewise, you would not "look" for literature..

6) Check the tense of the different sections of your memo. Previous work should be referred to in the past tense. Future work should be referred to in the future tense. Tense should be consistent within a section.

7) The first word after each bullet in a list should be consistent part of speech and tense.

8) Referring to attachments in the body of your memo will bring them to the readers' attention.

9) Questions addressed to a particular party (e.g. Faculty Advisor, External Mentor) should be highlighted in some way (e.g. bold text). See Action Items below.

10) As your projects progress, your team will begin dividing tasks. When refereeing to tasks in your memos, your team should explicitly state which group member will be responsible for the completion of the task. This is most easily accomplished by initializing the task or action. Taking charge of a task means that you are responsible for making sure the task is completed. Other members of your team may help complete the task.

\section{Assessment of Memos}

While many of the course outcomes will be measured through the final design report, the memos will be assessed with respect to the criteria listed below. These criteria all correspond to Course Outcomes 2 and 8 (from the syllabus) which reads:

2. Demonstrate multiple levels of communication of technical ideas: verbal, written, and graphical. 
8. Write effective project update memos.

Additionally, because the memos play a vital role in the writing process, it is critical that they are assessed to effectively guide you.

\begin{tabular}{|c|c|c|c|c|c|}
\hline & $\begin{array}{c}\text { Beginning } \\
1\end{array}$ & $\begin{array}{c}\text { Developing } \\
2\end{array}$ & $\begin{array}{c}\text { Accomplished } \\
\mathbf{3}\end{array}$ & $\begin{array}{c}\text { Exemplary } \\
4\end{array}$ & Score \\
\hline Clarity & $\begin{array}{l}\text { Memo contains } \\
\text { undefined terms and } \\
\text { makes use of } \\
\text { superfluous, esoteric } \\
\text { language. Key points } \\
\text { are buried in text. }\end{array}$ & $\begin{array}{l}\text { Memo contains only a } \\
\text { few undefined terms, } \\
\text { but may still be } \\
\text { difficult to understand } \\
\text { because key points } \\
\text { are not emphasized. }\end{array}$ & $\begin{array}{l}\text { Effective writing using } \\
\text { concise, easily } \\
\text { understood language. } \\
\text { Key points are easily } \\
\text { identified. }\end{array}$ & $\begin{array}{l}\text { Clarity is outstanding } \\
\text { and may be followed } \\
\text { (although not } \\
\text { understood) by an } \\
\text { outside reader. }\end{array}$ & \\
\hline$\underline{\text { Completeness }}$ & $\begin{array}{l}\text { Memo is too brief } \\
\text { and does not include } \\
\text { enough detail to } \\
\text { understand reported } \\
\text { events. }\end{array}$ & $\begin{array}{l}\text { Memo includes } \\
\text { sufficient detail of } \\
\text { reported events but } \\
\text { does not clearly state } \\
\text { their significance. }\end{array}$ & $\begin{array}{l}\text { Memo includes sufficient } \\
\text { detail to fully understand } \\
\text { reported events and } \\
\text { their significance. }\end{array}$ & $\begin{array}{l}\text { Memo provides } \\
\text { excellent balance in } \\
\text { providing sufficient } \\
\text { detail and significance } \\
\text { without overwhelming } \\
\text { the reader. }\end{array}$ & \\
\hline Organization & $\begin{array}{l}\text { Memo reflects } \\
\text { "stream-of-thought" } \\
\text { writing with little } \\
\text { attention to logical } \\
\text { or visual structure. }\end{array}$ & $\begin{array}{l}\text { Memo follows a } \\
\text { structure which is not } \\
\text { fully exploited due to } \\
\text { "stream of thought" } \\
\text { writing. }\end{array}$ & $\begin{array}{l}\text { Memo follows a } \\
\text { structure but lacks visual } \\
\text { organization when } \\
\text { necessary. }\end{array}$ & $\begin{array}{l}\text { Memo follows a } \\
\text { recognizable structure } \\
\text { and is easy to follow } \\
\text { both logically and } \\
\text { visually. }\end{array}$ & \\
\hline $\begin{array}{c}\text { Writing } \\
\text { Style/Tone }\end{array}$ & $\begin{array}{l}\text { Writing reads like a } \\
\text { narrative. Language } \\
\text { is inappropriate for } \\
\text { intended audience. } \\
\text { Contains numerous } \\
\text { spelling and } \\
\text { grammatical errors. }\end{array}$ & $\begin{array}{l}\text { Inappropriate (or } \\
\text { excessive) use of } \\
\text { passive voice. Minor } \\
\text { spelling or } \\
\text { grammatical errors. }\end{array}$ & $\begin{array}{l}\text { Writing reflects a } \\
\text { professional tone and } \\
\text { uses language } \\
\text { appropriate for the } \\
\text { intended audience. No } \\
\text { spelling or grammatical } \\
\text { errors. }\end{array}$ & $\begin{array}{l}\text { Writing is professional } \\
\text { and memo may be } \\
\text { passed on to higher } \\
\text { levels [of } \\
\text { management] without } \\
\text { hesitation. }\end{array}$ & \\
\hline
\end{tabular}

\section{Appendix D: BMEG 350 Final Presentation/Demo and Paper}

Over the course of the semester, each design group has followed a different path and therefore each group will have different results. To accommodate these differences, there are few suggestions concerning the technical content or method of communication. You should make effective use of the flexibility provided and take the opportunity to be creative. Specific questions should be address to Dr. Tranquillo.

\section{Final Presentation}

Your final presentation will be delivered on 5/1. It is suggested that you include:

1. An introduction to the medical phenomenon you studied

2. A brief overview of your experiment and LabVIEW program

3. A short live demonstration of your experiment (set up beforehand)

4. Your most significant results 


\section{Any conclusions you reached}

Your presentation should be no longer than 20 minutes and include time for questions. The focus should be on results and not the process you followed. It is likely that there will be audience members present with various levels of familiarity with your project, ranging from no prior knowledge to very detailed knowledge. Since this is a professional presentation, you should dress, speak and behave appropriately. Please place your final power point presentation and LabVIEW VI into Dr. Tranquillo's dropbox by 8am on 5/1.

\section{Final Paper}

The final paper must be deposited into Dr. Tranquillo's drop box by $5 \mathrm{pm}$ on $5 / 8$. The required format is the standard IEEE Engineering in Medicine and Biology (EMBS) and Control Systems Society (CSS) template (provided in a separate document). The length of your report may be no longer than 2 pages including all figures, citations and appendices. The short length of this paper will require you to condense your text and only include tables and figures that are informative. Although you may use the presentation suggestions above as a guide, the content of the final paper will be up to each group.

\section{Appendix E: BMEG 300 Poster Presentation}

This document is intended to provide you with brief guidelines for creating and printing your BMEG 300 Femlab project posters. Currently, the poster presentation is scheduled for Tuesday, May $2^{\text {nd }}$ from 1:00pm to 2:00pm. During the poster presentation, you will be required to be at your poster for 30 minutes in order to answer any questions regarding your posters.

\section{Poster Creation}

Posters are most easily created by printing a single, large PowerPoint slide using the large HP plotter in Dana 217. Below are general formatting guidelines for the poster:

- The poster should be formatted in the portrait orientation with overall dimensions of 36 inches wide by 56 inches tall.

- You may feel free to use the BMEG 300 Poster Template file in Dr. Cavanagh's public space or you may choose to find another (e.g., from the web). A simple Google search under "PowerPoint poster templates" will provide a number of options. Be sure to correctly format the dimensions. The color scheme of the template can be changed so you can customize it to your liking.

- You should be sure to use fonts that can be read from 6 feet away for the text in the poster and a title font that can be read from a longer distance.

- A poster is meant to contain the slides you would use were you giving a talk on this work. Therefore, you need to include some or all of the central elements of a report including: introduction, background, model description, example mesh, parameter space examined, values of constants, model limitations, results, discussion of the physical meaning of the results, relation back to physiological problem, conclusions, bibliography.

- A key is to try to use *as little text* as possible and use as many pictures/images/graphs as you can. All figures should have associated brief text 
descriptions. The poster should be able to be understood on its own, but YOU will be standing next to it to explain, so keep that in mind. Feel free to look at the many posters hanging around Dana and Breakiron.

\section{Poster Printing}

In order to provide you the ability to view a draft version of your poster, each student will be allowed to print two versions of the poster. One will be done on Friday, April $28^{\text {th }}$ and the second will be on Monday, May $1^{\text {st }}$. As there are many other students who will be printing at this time, we will all need to be flexible throughout this process. Before printing any poster, each student should go to a classroom and project the slide on the screen to get an initial feel as to how it looks. This can save a lot of time. Once your first version is done, please email Dr. Cavanagh and he can let you into Dana 217. If the room is already open, feel free to go ahead and print. With the poster printed, students can identify any edits that need to be made and can let Dr. Cavanagh know on Monday when they are ready to print the final version.

\section{Poster Session}

Posters will be mounted on a 40" x 60 " piece of foam board for the poster session. As the foam board comes in 40" $\mathrm{x} 30$ " pieces, you will tape two pieces together to make the full board. Students are reminded that while you may keep your poster, the foam board needs to be returned to Dana 223 after the poster session. 